\title{
High diversity in Keratella cochlearis (Rotifera, Monogononta): morphological and genetic evidence
}

\author{
Adam Cieplinski - Thomas Weisse • \\ Ulrike Obertegger
}

Received: 16 November 2015/Revised: 21 March 2016/Accepted: 15 April 2016/Published online: 17 May 2016

(C) The Author(s) 2016. This article is published with open access at Springerlink.com

\begin{abstract}
Rotifers are ubiquitous freshwater animals for which many complexes of cryptic species (i.e. distinct species that are morphologically difficult to distinguish) are described. Keratella cochlearis occurs globally and shows a wide phenotypic diversity indicating the potential presence of a species complex. We sampled lakes of the Trentino-South Tyrol region (Italy) and investigated mitochondrial genetic diversity in $K$. cochlearis in relation to detailed lorica measurements. We sequenced the mitochondrial cytochrome $c$ oxidase subunit I and used the generalised mixed Yule coalescent approach, Poisson tree process model and automatic barcode gap discovery to delimit mitochondrial groups, associated with putative
\end{abstract}

Electronic supplementary material The online version of this article (doi:10.1007/s10750-016-2781-z) contains supplementary material, which is available to authorized users.

Guest editors: M. Devetter, D. Fontaneto, C. D. Jersabek, D. B. Mark Welch, L. May \& E. J. Walsh / Evolving rotifers, evolving science

A. Cieplinski $(\bowtie) \cdot$ U. Obertegger

Department of Sustainable Agro-ecosystems and Bioresources, Research and Innovation Centre, Fondazione Edmund Mach (FEM), Via E. Mach 1, 38010 San Michele all'Adige, TN, Italy

e-mail: adam.cieplinski@fmach.it

A. Cieplinski - T. Weisse

Research Institute for Limnology, University of Innsbruck, Mondseestraße 9, 5310 Mondsee, Austria evolutionary significant units (ESUs). Based on 248 sequences, eight putative ESUs were indicated that could only partially be delimited by lorica morphology. Specifically, several morphological characteristics (i.e. spinelets, bended median ridge, and posterior spine) were found in specimens of different putative ESUs, and thus, these characters seem to be of poor discriminatory value. Furthermore, different putative ESUs of $K$. cochlearis were found in the same lake. We conclude that the high mitochondrial genetic diversity may be linked to tolerance of $K$. cochlearis to varying environmental conditions.

Keywords Rotifera - GMYC · PTP · Lorica measurements $\cdot$ NMDS $\cdot$ Lauterborn

\section{Introduction}

Biodiversity is currently under threat, and our perception of species loss is highly dependent on accurate estimates of species richness. However, estimates of species richness are often impaired by the occurrence of cryptic species (i.e. species that are impossible or difficult to distinguish based on their morphology) in diverse groups such as protists (Foissner, 2006), ants (Fournier et al., 2012), harvestmen (Arthofer et al., 2013), and rotifers (Gómez \& Snell, 1996). Understanding how and why species occur is one of the fundamental aspects in ecology (Gaston, 2000). 
Evidence on cryptic species diversity in rotifers, subclass Monogononta, is growing and challenges our understanding of rotifer biodiversity. In monogonont rotifers, cryptic species complexes have been described for species such as Brachionus plicatilis (Gómez \& Serra, 1995; Gómez \& Snell, 1996; Gómez et al., 2002), B. calyciflorus (Schröder \& Walsh, 2007; $\mathrm{Xi}$ et al., 2011), Epiphanes senta (Gilbert \& Walsh, 2005), Lecane spp.(García-Morales \& Elías-Gutiérrez, 2013), Polyarthra dolichoptera (Obertegger et al., 2014), Synchaeta spp. (Obertegger et al., 2012), and Testudinella clypeata (Leasi et al., 2013). The occurrence of cryptic species is often related to rotifer ubiquity and their wide tolerance to environmental parameters such as salinity (Ciros-Pérez et al., 2001a), temperature (Gómez \& Snell, 1996; Ortells et al., 2003; Papakostas et al., 2012) or total phosphorus (Obertegger et al., 2012).

Keratella cochlearis Gosse, 1851 can be found in most freshwater lakes and ponds all over the world (Green, 1987). In fact, the whole genus Keratella is considered eurytopic and cosmopolitan (Segers \& De Smet, 2008), and this makes the genus a good candidate for investigating the occurrence of cryptic species. Lauterborn (1900) described several morphotypes in $K$. cochlearis, and his detailed descriptions and drawings were the basis for following taxonomic work (e.g. Ahlstrom, 1943; RuttnerKolisko, 1974; Koste, 1978). The morphotypes described by Lauterborn (1900) encompass three series (macracantha-typica-tecta, hispida, and irregularis) and the group of robusta. These morphological varieties of $K$. cochlearis are different with respect to lorica length (LL), spine length, presence of spinelets on the lorica, and the course of the median ridge. Here, we give an overview of the Lauterborn (1900) series and a German to English translation of Lauterborn's (1900) descriptions. In the macracantha-typica-tecta series (Lauterborn's 1900, Figs. 1-10), the posterior spine is as long as the lorica or even longer, and the basis of the spine is so wide that it is difficult to decide where the spine begins and the lorica ends. The areolation is present on half of the spine, and only the distal part is smooth and pointed. In lateral view, the spine points to left or right, and this is according to Lauterborn (1900) not an important feature. Along the series, the reduction of the posterior spine is notable until it disappears completely. Lauterborn
(1900) concluded that it is impossible to draw a line between the different morphotypes of the macracantha-typica-tecta series that only differ in size and posterior spine length (PSL). The morphotypes of the hispida (Lauterborn's 1900, Figs. 11-14) and irregularis series (Lauterborn's 1900, Figs. 15-20) show different morphological elements with respect to the macracantha-typica-tecta series, and size differences are not important. In the hispida series, small spines (called "Pusteln" after Lauterborn, 1900 and "spinelets" after Ahlstrom, 1943) are present and can be so dense that the areolation and the borders of the plates become invisible. The morphotypes of the hispida series can be considered the forma punctata of the tecta series. Only for Lauterborn's (1900), Fig. 11, closely related to macracantha, and for Lauterborn's (1900), Fig. 27, closely related to tecta, the name forma punctata is given. In the irregularis series, the ridge is bended to the left in dorsal view, and a displacement of the facets is visible that leads to pointed bumps (called "Höcker" by Lauterborn, 1900) on the facets and an additional facet (called facet $X$ by Lauterborn, 1900). In addition, the basal margin is divided into small posterior carinal facets. Similar to the hispida series, the lorica has small pointed spinelets on the intersection of the areolation. The robusta group (Lauterborn's 1900, Figs. 21-23) is not a series because no direction of morphological variations can be distinguished. Characteristic for this group is the wide base of the posterior spine that is the elongation of the ventral part of the lorica, the hooked form of the anterior spines, and the slightly bended median ridge.

Considering the wide morphological variability of Keratella morphotypes, Lauterborn (1900) already hypothesised a subspecies status of some morphotypes. In fact, Ahlstrom (1943) and Eloranta (1982) erected the series irregularis and hispida to separate species. However, Hofmann (1983), who did not recognise transitional forms between the morphotypes cochlearis, irregularis, and tecta as described by Lauterborn (1900), questioned the validity of the Lauterborn cycles. Especially, the presence and length of the posterior spine seems to be a morphological character whose suitability for discriminating species is questionable. In eutrophic habitats, $K$. cochlearis tends to be smaller and has smaller posterior spines than in oligotrophic habitats (Green, 2007). 
Furthermore, LL and PSL are longer with decreasing water temperature (e.g. Green, 1981, 2005; BielanskaGrajner, 1995) and in the presence of predators (Conde-Porcuna et al., 1993; Green, 2005). Water conditioned with predators (i.e. Asplanchna spp., cyclopoid copepods) can induce spine formation in offspring of tecta (Stemberger \& Gilbert, 1984). Derry et al. (2003) found a high mitochondrial genetic difference $[4.4 \%$ cytochrome $c$ oxidase subunit I (COI) sequence divergence] between spined and spineless individuals of $K$. cochlearis and hypothesised the presence of cryptic diversity within these morphotypes. Furthermore, the various morphotypes of $K$. cochlearis show different tolerances to temperature (Berzinš̌ \& Pejler, 1989a), oxygen content (Berzinsš \& Pejler, 1989b), trophic state, and conductivity (Berzinšs \& Pejler, 1989c). The wide tolerances to environmental conditions could also indicate that $K$. cochlearis is a cryptic species complex composed of species with narrower ecological preferences than when taken as a complex.

Here, we identified mitochondrial DNA (mtDNA) groups and compared their lorica morphology in a complementary approach as recommended by Schlick-Steiner et al. (2006), Fontaneto et al. (2015) and Mills et al. (2016). Combining genetic information with other species-bound aspects such as species morphology and ecology or biochemistry of species habitat can result in a more robust species delimitation than when using genetic information alone (SchlickSteiner et al., 2006; Fontaneto et al., 2015; Mills et al., 2016). We hypothesised that $K$. cochlearis is a complex of putative evolutionary significant units (ESUs) and that it is possible to delimit ESUs based on lorica measurements. In fact, in B. plicatilis some clusters of cryptic species [B. plicatilis (sensu stricto) L., B. rotundiformis SS, B. rotundiformis SM] can be distinguished based on body length differences (CirosPérez et al., 2001b). Closely related species might have similar niches according to the phylogenetic niche conservatism theory (e.g. Wiens \& Graham, 2005; Wiens et al., 2010), and this may lead to competitive exclusion (Violle et al., 2011). Thus, ESUs with their close phylogenetic relationship might be especially prone to competitive exclusion; however, co-occurrence of rotifer cryptic species has been reported (Obertegger et al., 2014). Thus, we also investigated temporal co-existence of putative ESUs of $K$. cochlearis and hypothesised little co-occurrence.

\section{Materials and methods}

\section{Sampling}

From March to November 2014, six lakes in the Trentino-South Tyrol (Italy) region were sampled monthly. These lakes (called further the "core lakes") cover a wide range of environmental parameters (Table 1). In addition, we also sampled 11 additional lakes from Trentino-South Tyrol in the years 2010, 2013, and 2015 during summer and winter to cover a larger geographical area and altitudinal range (Table 1; Fig. 1). Environmental parameters were based on published data (IASMA, 1996-2000) and own analyses (Table 1). At the deepest site of each lake, plankton samples were collected with a $20 \mu \mathrm{m}$ (Apstein) or $50 \mu \mathrm{m}$ (Wisconsin) plankton net depending on lake depth. Both mesh sizes were small enough to effectively collect specimens of $K$. cochlearis (length $>74 \mu \mathrm{m}$, width $>60 \mu \mathrm{m}$; Lauterborn, 1900; Koste, 1978).

Measurements of specimens and morphological observations

For the core lakes and Lake Caldonazzo (July sample), single specimens of $K$. cochlearis were isolated under a stereomicroscope and photographed (Leica DC $300 \mathrm{~F}$ camera, Leica IM1000 software) in dorsal and lateral view under a compound microscope. The following measurements were taken: PSL, LL excluding anterior and posterior spines, total LL (TLL) including all appendages, lorica width (LW) at its widest part, LW at the mouth opening region ("head width", HW), anterolateral dorsal spine length (ALS), anterointermediate dorsal spine length (AIS), anteromedian dorsal spine length (AMS), and posterior spine angle (PSA, Fig. 2). For the measured specimens, we also observed the main characteristics of the dorsal plate, important to discriminate morphotypes. Measured specimens were subject to DNA extraction and sequencing. However, we could not obtain sequences for all measured specimens.

DNA extraction and amplification

Specimens of $K$. cochlearis from the core and the additional lakes were sequenced to investigate presence of putative ESUs. Cryptic species complexes in 
Table 1 Environmental data on sampled lakes

\begin{tabular}{|c|c|c|c|c|c|c|c|c|c|c|c|c|}
\hline Lakes & Alti & Area & Depth & $\mathrm{TP}$ & $\mathrm{NO}_{3}$ & $\mathrm{Si}$ & $\mathrm{SO}_{4}$ & $\mathrm{Cl}$ & $\mathrm{pH}$ & Cond & Temp & Trophic states \\
\hline Kaltern $^{\mathrm{c}}$ & 215 & 131 & 5 & 13 & 1,006 & 2 & 74 & 8 & 8.3 & 507 & 18 & Meso \\
\hline Terlago $^{c}$ & 414 & 11.9 & 10 & 31 & 885 & 3.2 & 14.4 & 5.8 & 8.0 & 389 & 23 & $\mathrm{Eu}$ \\
\hline Levico & 440 & 116.4 & 38 & 15 & 225 & 2.65 & 36 & 5 & 8 & 275 & 14 & Meso \\
\hline Caldonazzo & 449 & 562.7 & 47 & 21 & 314 & 3.7 & 26.3 & 5.8 & 8.0 & 312 & 22 & Meso \\
\hline Großer Montiggler & 492 & 17.8 & 12.5 & 50 & 13 & 0.55 & 9.6 & 8.5 & 7.9 & 293 & 6 & $\mathrm{Eu}$ \\
\hline Canzolino & 540 & 7.1 & 15 & 56 & 510 & 3.6 & 27 & 4.5 & 7.4 & 257 & 23 & $\mathrm{Eu}$ \\
\hline Vahrn $^{\mathrm{c}}$ & 678 & 1.5 & 3.5 & 13 & 70 & 3.3 & 5.3 & 1.4 & 6.6 & 57 & 23 & Meso \\
\hline Raier Moos & 835 & 0.7 & 5 & 39 & 0 & 2.7 & 19.6 & 7.9 & 8.3 & 368 & 19 & $\mathrm{Eu}$ \\
\hline Serraia & 974 & 44.4 & 17 & 34 & 458 & 9.7 & 7.3 & 2.8 & 7.6 & 116 & 22 & $\mathrm{Eu}$ \\
\hline Völser Weiher & 1,056 & 1.7 & 4 & 14 & 71 & 0.4 & 11.3 & 0.9 & 24 & 252 & 24 & Meso \\
\hline Lavarone & 1,100 & 5.2 & 15 & 28 & 276 & 2.6 & 8 & 6.9 & 7.8 & 291 & 21 & $\mathrm{Eu}$ \\
\hline Wolfsgruben & 1,176 & 3.9 & 5.4 & 33 & 55 & 2.0 & 9.3 & 3.1 & 8 & 114 & 8 & $\mathrm{Eu}$ \\
\hline Tovel $^{\mathrm{c}}$ & 1,178 & 38.2 & 39 & 4 & 318 & 1.3 & 1.7 & 0.3 & 7.9 & 192 & 15 & Oligo \\
\hline Antholz & 1,642 & 43.3 & 38 & 7 & 226 & 2.6 & 12.6 & 0.5 & 7.5 & 90 & 17 & Oligo \\
\hline Glittner $^{\mathrm{c}}$ & 2,151 & 0.05 & 1 & 129 & 11 & 0.2 & 0.6 & 0.4 & 6.1 & 9 & 12 & Meso \\
\hline $\operatorname{Radl}^{\mathrm{c}}$ & 2,258 & 0.8 & 6 & 13 & 21 & 0.5 & 15 & 0.4 & 7.7 & 92 & 13 & Meso \\
\hline Crespeina & 2,374 & 0.6 & 7 & 11 & 30 & 0.2 & 1.5 & 0.2 & 8.8 & 157 & 12 & Oligo \\
\hline
\end{tabular}

The superscript ${ }^{\mathrm{c}}$ indicates the core lakes ordered by altitude (alti, $\mathrm{m}$ above sea level): area $\left(\times 10,000 \mathrm{~m}^{2}\right)$, depth (m), total phosphorus $\left(\mathrm{TP}, \mu \mathrm{g}^{-1}\right)$ at spring overturn, nitrate $\left(\mathrm{NO}_{3}, \mu \mathrm{g} \mathrm{1^{-1 }}\right)$, reactive silica $\left(\mathrm{Si}, \mathrm{mg} \mathrm{l}^{-1}\right)$, sulphate $\left(\mathrm{SO}_{4}, \mathrm{mg} \mathrm{l}^{-1}\right)$, chloride $\left(\mathrm{Cl}, \mathrm{mg} 1^{-1}\right)$, conductivity (cond, $\mu \mathrm{S} \mathrm{cm}^{-1}$ ), mean summer surface temperature (temp), and trophic state (eu eutrophic, meso mesotrophic, oligo oligotrophic)

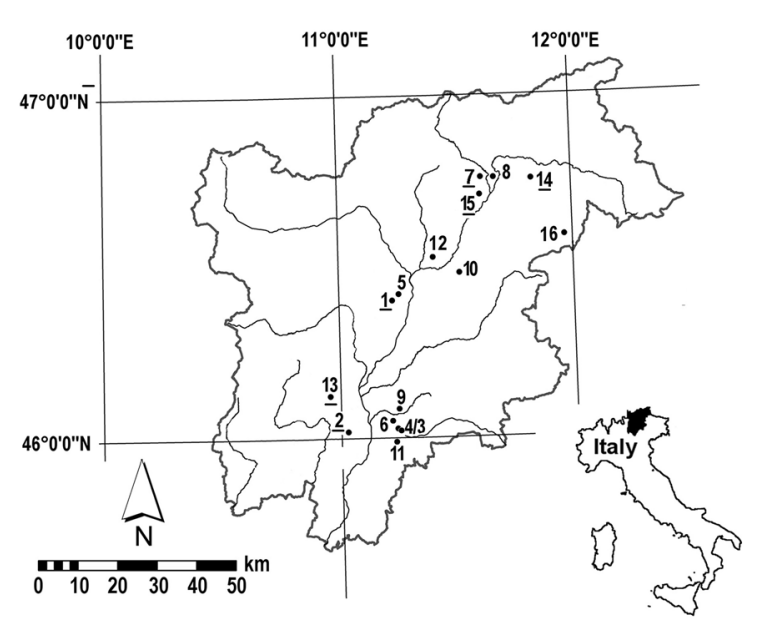

Fig. 1 Sampled lakes in the Trentino-South Tyrol region, (1) Kaltern $^{\mathrm{c}}$, (2) Terlago ${ }^{\mathrm{c}}$, (3) Levico, (4) Caldonazzo, (5) Großer Montiggler, (6) Canzolino, (7) Vahrn ${ }^{\mathrm{c}}$, (8) Raier Moos, (9) Serraia, (10) Völser Weiher, (11) Lavarone, (12) Wolfsgruben, (13) Tovel ${ }^{\mathrm{c}}$, (14) Glittner ${ }^{\mathrm{c}}$, (15) Radl ${ }^{\mathrm{c}}$, and (16) Crespeina; core lakes (superscript ${ }^{\mathrm{c}}$ ) are underlined on the map

rotifers are often inferred based on the mitochondrial COI (Suatoni et al., 2006; Obertegger et al., 2012, 2014; Leasi et al., 2013; Fontaneto, 2014;
Malekzadeh-Viayeh et al., 2014). We extracted DNA from single live individuals with $35 \mu$ of Chelex (InstaGeneMatrix, Bio-Rad, Hercules, CA, USA). The COI gene was amplified using LCO1490 (5'-GGT CAA CAA ATC ATA AAG ATA TTGG- ${ }^{\prime}$ ) and HCO2198 (5'-TAA ACT TCA GGG TGA CCA AAA AAT CA-3 ${ }^{\prime}$ ) primers (Folmer et al., 1994). PCR cycles consisted of initial denaturation at $95^{\circ} \mathrm{C}$ for $10 \mathrm{~min}$, followed by 50 cycles at $95^{\circ} \mathrm{C}$ for $45 \mathrm{~s}, 46^{\circ} \mathrm{C}$ for $45 \mathrm{~s}$ and $72^{\circ} \mathrm{C}$ for $1.05 \mathrm{~min}$, and a last step at $72^{\circ} \mathrm{C}$ for $7 \mathrm{~min}$. For each sample, we used $2 \mu \mathrm{l}$ of DNA extract and $23 \mu \mathrm{l}$ of master mix solution. Master mix proportions for one sample were $12.7 \mu \mathrm{l}$ distilled water, $2.5 \mu \mathrm{l}$ of buffer, $3.5 \mu \mathrm{MgCl}_{2}(25 \mathrm{mM}), 1 \mu \mathrm{l}$ primer HCOI2198, $1 \mu \mathrm{l}$ primer LCOI1490, $2 \mu \mathrm{l}$ dNTP $(10 \mathrm{mM})$, and $0.3 \mu \mathrm{l}$ AmpliTaq Gold ${ }^{\circledR} 360$ DNA polymerase (Thermo Fisher Scientific, Italy). For postPCR purification, we used ExoSAP-IT ${ }^{\circledR}$ PCR product cleanup (Affymetrix USB, USA).

Phylogenetic reconstruction

We constructed the phylogenetic tree using a maximum likelihood (ML) and Bayesian inference (BI) 


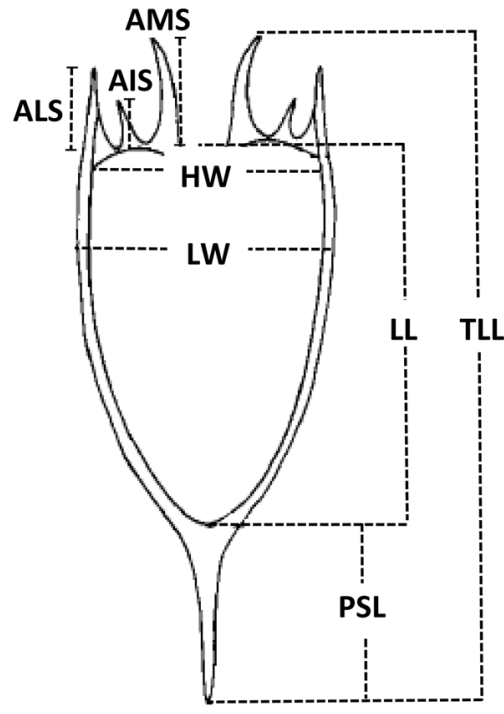

Fig. 2 Lorica drawing of $K$. cochlearis with measured parameters; lorica length excluding anterior and posterior spines $(L L)$, posterior spine length $(P S L)$, total lorica length including all appendages $(T L L)$, lorica width at its widest part $(L W)$, posterior spine angle (PSA), anterolateral dorsal spine length $(A L S)$, anterointermediate dorsal spine length $(A I S)$, anteromedian dorsal spine length $(A M S)$, and lorica width beneath the anterior spines ("head width", $H W$ )

approach. The model of evolution for the phylogenetic reconstruction was $\mathrm{HKY}+I+G$, selected with ModelGenerator v0.85 (Keane et al., 2006). The selected model was implemented into PhyML 3.0 (Guindon \& Gascuel, 2003) to perform ML reconstruction using the approximate likelihood ratio test to evaluate node support. For BI, we used BEAST v1.8.0 (Drummond et al., 2012) with the following settings: uncorrelated lognormal relaxed clock (mean molecular clock rate set as normal), HKY $+I+G$ substitution model, and the birth-death model. The posterior probability distribution was estimated with Markov chain Monte Carlo (MCMC) sampling, which was run for 100 million generations, sampling every 10,000th generation. We used Tracer v1.5 (Rambaut et al., 2014) to investigate for convergence and the correctness of the MCMC model and to determine the burnin. We used TreeAnnotator v1.7.5 to summarise trees and discard the first 2,000 trees as burn-in. As outgroup sequences, we used B. urceolaris (Genbank accession number EU499787), B. rotundiformis (JX239163), and B. plicatilis (JX293050), all belonging to the same family (i.e. Brachionidae) as Keratella.
Inference of mtDNA groups

We inferred mtDNA groups within $K$. cochlearis with the generalised mixed Yule coalescent (GMYC) approach (Fujisawa \& Barraclough, 2013), the Poisson tree process model (PTP; Zhang et al., 2013), and the automatic barcode gap discovery (ABGD; Puillandre et al., 2012) and compared the results. For all methods, the outgroup was excluded prior to the analyses. We took the results of the GMYC approach as our baseline results because previously rotifer diversity was investigated by it for different species (Obertegger et al., 2012, 2014; Leasi et al., 2013; Malekzadeh-Viayeh et al., 2014). The GMYC approach is based on branching rates along an ultrametric tree (here from BEAST) to distinguish between species-level (Yule, slower) and populationlevel (coalescent, faster) branching rates. This model identifies GMYC ESUs. For the GMYC approach, we used R 3.0.2 (R Core Team, 2012), library splits (Ezard et al., 2009). The PTP model (http://species.hits.org) uses a phylogenetic tree as input (here the ML tree produced in PhyML 3.0.) and applies coalescent theory to distinguish between population-level and species-level processes. Similarly to GMYC, PTP assumes that there are less intraspecific substitutions than interspecific substitutions because they have less time to accumulate. This method does not require an ultrametric tree and has been shown to match other methods of species delimitation in rotifers (Tang et al., 2014) and copepods (Blanco-Bercial et al., 2014). Two types of PTP were used: ML (PTP-ML) approach and Bayesian approach (PTP-BA). The ABGD (http:// www.abi.snv.jussieu.fr/public/abgd/abgdweb.html) deliminates species without any a priori assumptions. It detects the gaps in the distribution of genetic pairwise distances. This method has been successfully used to delimit species of the meiofauna (Tang et al., 2012; Leasi et al., 2013). Here, all aligned $K$. cochlearis sequences were used for ABGD.

We based our phylogenetic reconstructions and inference of mtDNA groups on a single mitochondrial gene (COI), and this may gave a biased estimate on genetic diversity. A higher evolutionary rate of COI with respect to other nuclear markers (Tang et al., 2012), mitochondrial introgression (reported for $B$. calyciflorus by Papakostas et al., 2016 but not for $E$. senta by Schröder \& Walsh, 2010), and/or unresolved ancestral polymorphism (Funk \& Omland, 2003) 
could bias our inference on species diversity. Recently, it has also been shown that the methods we used give biased results in species poor datasets (Dellicour \& Flot, 2015). Thus, considering this uncertainty, our statements are about putative ESUs based on the inference of mtDNA groups.

Statistical analysis of measurements in relation to putative ESUs

Green $(1981,1987)$ reports a positive correlation between LL and PSL in $K$. cochlearis from various lakes of the Auvergne region in France. To assess the general validity of this correlation, we considered only those specimens that were measured and for which we obtained COI sequences. We divided specimens into putative ESUs and investigated the sign and significance of the correlation (Pearson correlation coefficient; $r_{\mathrm{P}}$ ) between LL and PSL.

We performed a univariate statistical analysis and a multivariate ordination method to investigate if putative ESUs could be distinguished based on morphology. As univariate statistical analysis, we used a oneway ANOVA and post hoc Tukey multiple comparisons. We performed generalised least squares modelling to allow for dependence of measurements of ESUs coming from the same lake and checked homogeneity of residuals graphically. As multivariate ordination method, we performed non-metric multidimensional scaling (NMDS). In NMDS, Bray-Curtis distance matrix was used on centred and standardised measurement data. In NMDS, the goodness of fit was investigated by the Shepard plot that shows the relationship between the inter-object distances in NMDS and Bray-Curtis dissimilarity. The residuals of this relationship were used to calculate Kruskal's stress $(S) ; S$ values $<0.2$ are considered statistically meaningful (Quinn \& Keuogh, 2002). We, furthermore, performed a linear discriminant analysis (LDA) to investigate the discriminatory power of lorica morphology to separate ESUs. We tested for homogeneity of within-ESU covariance matrices.

We also investigated the correlation between phylogenetic and morphological diversity. Phylogenetic diversity was calculated as distance matrix based on the ultrametric tree, and morphological diversity as a distance matrix based on mean morphological values of ESUs. The correlation between both distance matrices was investigated by a Mantel test.

For statistical analyses, we used the library nlme (Pinheiro et al., 2012), MASS (Venables \& Ripley, 2002), vegan (Oksanen et al., 2015), and multcomp (Hothorn et al., 2008) in R 3.0.2 (R Core Team, 2012).

\section{Results}

Inference of putative ESUs

We obtained 248 sequences of the COI gene of $K$. cochlearis (Genbank accession number: supplementary material Table s1). These sequences comprised 57 haplotypes. The GMYC approach indicated eight ESUs (single threshold GMYC: likelihood of the null model $=261.4$; likelihood of the GMYC approach $=$ 269.5; $P<0.001$; confidence interval $=8-14)$, that are hereafter called GMYC ESUs. Uncorrected genetic distances within GMYC ESUs were below 6.2\% with ESU 5 showing the lowest and ESU 8 the highest within-ESU distance (Table 2). Distances between GMYC ESUs ranged from 9\% (ESU 7 vs. 8) to $33 \%$ (ESU 8 vs. 3) with an overall average value of $21 \%$ (Table 3 ).

The ABGD and the PTP-ML grouped the same haplotypes in the same ESUs as GMYC (Fig. 3). However, PTP-BA, split GMYC ESU 3 into three and ESU 6 into five units (Fig. 3).

GMYC ESUs occurrence in lakes

GMYC ESUs 3 and 7 were found in seven lakes, ESU 8 in six, ESU 5 in five, and ESU 4 and 1 were found only in two and ESU 2 only in one lake (Fig. 3; Tables s2, s3 supplementary material). Considering temporal co-existence of GMYC ESUs in the core lakes, no clear pattern emerged (Table s3 supplementary material). Generally, GMYC ESUs co-occurred, except for ESU 2 that was found only once in Lake Radl, despite monthly sampling during summer 2013. ESUs 3 and 7 co-occurred most often in different lakes. ESU 3 was almost always present throughout the sampling period in Lakes Kaltern and Terlago (Table s3 supplementary material); similarly, ESU 5 in Lake Glittner and ESU 6 in Lake Tovel were present 
Table 2 Report of the uncorrected genetic distances within GMYC ESUs of $K$. cochlearis, number of haplotypes, number of individuals, and mean, median, minimum (min), and maximum (max) of distances

\begin{tabular}{lcccccc}
\hline GMYC ESUs & Individuals & Number of haplotypes & Mean & Median & Min & Max \\
\hline ESU 1 & 2 & 1 & & & & \\
ESU 2 & 5 & 1 & 0.02 & 0.04 & 0.000 & 0.05 \\
ESU 3 & 60 & 13 & 0.01 & 0.02 & 0.002 & 0.02 \\
ESU 4 & 8 & 4 & 0.01 & 0.01 & 0.010 & 0.01 \\
ESU 5 & 65 & 3 & 0.02 & 0.01 & 0.002 & 0.04 \\
ESU 6 & 67 & 8 & 0.02 & 0.01 & 0.002 & 0.04 \\
ESU 7 & 13 & 12 & 0.02 & 0.02 & 0.002 & 0.06 \\
ESU 8 & 28 & 15 & & & &
\end{tabular}

Table 3 Report of the uncorrected genetic distances between GMYC ESUs of $K$. cochlearis, mean, and median values equal to the second decimal point (mean $\approx$ median), minimum, and maximum (minlmax) values of distances

\begin{tabular}{|c|c|c|c|c|c|c|c|}
\hline & ESU 1 & ESU 2 & ESU 3 & ESU 4 & ESU 5 & ESU 6 & ESU 7 \\
\hline \multicolumn{8}{|c|}{ Mean $\approx$ median } \\
\hline ESU 2 & 0.29 & & & & & & \\
\hline ESU 3 & 0.21 & 0.28 & & & & & \\
\hline ESU 4 & 0.22 & 0.27 & 0.18 & & & & \\
\hline ESU 5 & 0.22 & 0.28 & 0.18 & 0.19 & & & \\
\hline ESU 6 & 0.23 & 0.28 & 0.20 & 0.20 & 0.12 & & \\
\hline ESU 7 & 0.21 & 0.30 & 0.18 & 0.19 & 0.15 & 0.15 & \\
\hline ESU 8 & 0.22 & 0.27 & 0.18 & 0.19 & 0.15 & 0.14 & 0.13 \\
\hline \multicolumn{8}{|l|}{ MinlMax } \\
\hline ESU 2 & 0.29 & & & & & & \\
\hline ESU 3 & 0.2010 .23 & 0.2710 .28 & & & & & \\
\hline ESU 4 & $0.22 \mid 0.23$ & 0.2710 .28 & $0.16 \mid 0.19$ & & & & \\
\hline ESU 5 & 0.22 & 0.2810 .28 & 0.1810 .19 & $0.19 \mid 0.20$ & & & \\
\hline ESU 6 & $0.22 \mid 0.24$ & 0.2810 .29 & $0.19 \mid 0.20$ & $0.18 \mid 0.21$ & $0.11 \mid 0.13$ & & \\
\hline ESU 7 & $0.18 \mid 0.23$ & 0.2910 .34 & $0.15 \mid 0.21$ & $0.16 \mid 0.21$ & $0.12 \mid 0.16$ & 0.1110 .17 & \\
\hline ESU 8 & 0.2010 .24 & 0.2610 .33 & $0.16 \mid 0.20$ & $0.18 \mid 0.23$ & $0.14 \mid 0.17$ & 0.0910 .17 & $0.11 \mid 0.15$ \\
\hline
\end{tabular}

throughout the sampling period (Table s3 supplementary material).

\section{Morphology}

We obtained lorica measurements from 138 individuals of $K$. cochlearis that could also be attributed to GMYC ESUs based on their COI sequence (Table 4; Table s3 supplementary material). For ESUs 1 and 2, no measurements were obtained, and for ESU 7, only one specimen was measured (Table 4). All specimens of ESU 4 and three specimens of ESU 6 did not have a spine, while the other measured specimens had a spine of varying length (Table 4).

The correlation between LL and PSL was different when based on all specimens $\left(r_{\mathrm{P}}=0.68 ; P<0.001\right)$ compared to splitting it into GMYC ESUs: for ESUs 3 and 6 , the correlation was higher $\left(r_{\mathrm{P}}=0.76\right.$ and 0.77 , respectively; $P<0.001)$ than the overall one, and no correlation was found for ESU 4 (spineless specimens), ESU $5\left(r_{\mathrm{P}}=0.13 ; P=0.41\right)$, and ESU 8 ( $r_{\mathrm{P}}=0.76 ; P=0.13$; Fig. 4$)$.

We tested for significant differences in LL, PSL, and PSA between GMYC ESUs by ANOVA and following post hoc multiple comparisons tests by mixed modelling. LL and PSA were different between four ESUs, and PSL differed between three ESUs (Table 5). Based on all three measurements, ESU 8 was different from ESUs 3 and 5 (Table 5).

In NMDS with all measurements $(S=0.13)$, a gradient from specimens of ESU 5 to specimens of ESU 4 and spineless specimens of ESU 6 was evident. To get a clearer picture on the relationships between ESUs with spines, we excluded ESU 4 and the three 


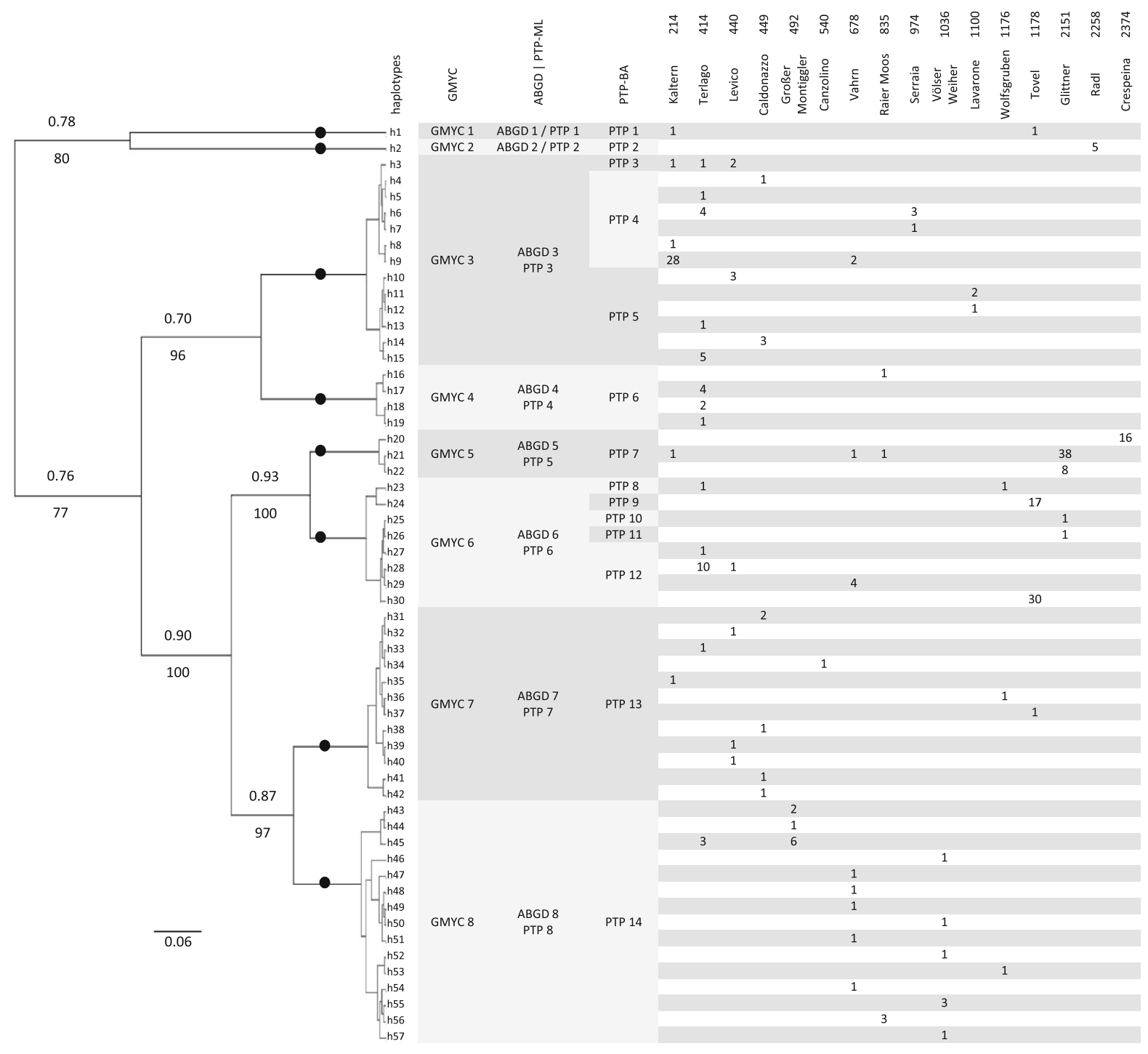

Fig. 3 Phylogenetic relationships of the 57 COI haplotypes of $K$. cochlearis. The phylogenetic tree was created with Bayesian interference analysis showing all compatible groupings and with average branch lengths proportional to numbers of substitutions per site under a HKY $+I+G$ substitution model. Posterior probabilities from the Bayesian reconstruction and approximate likelihood ratio test support values from the maximum

spineless specimens from ESU 6 from the NMDS analysis. In this NMDS with measurements of spined individuals $(S=0.17$ ), specimens of ESUs 5 and 8 formed distinct clusters while specimens from ESUs 3 and 6 were mixed (Fig. 5). In the LDA based on PSL, LL, and PSA, the percent correct assignment of ESUs varied (ESU 3: 69\%, ESU 5: 83\%, ESU 6: 53\%, ESU 8: $50 \%)$. likelihood are shown below and above each branch, respectively. The inference of putative ESUs by $G M Y C, A B G D$, and $P T P$ based on maximum likelihood (PTP-ML) and Bayesian inference (PTP-BI) is shown. Lakes were sorted according to increasing altitude (elevation in the upper line, metres above sea level). The number of sequences for each haplotype per lake is given in each line

We noted the presence of spinelets (Fig. 6), additional facets, and bending of the ridge (Fig. 4) in some specimens and linked these characteristics to their association to GMYC ESUs. We observed across ESUs the presence of spinelets, additional facets, and bending of the ridge (Table 6). In addition, we observed small humps in the middle of the areolation section and the symmetrically situated lateral antenna (Fig. 6). 
Table 4 Length measurements of main lorica characteristics based on 138 specimens of $K$. cochlearis, lorica length (excluding anterior and posterior spines, LL), posterior spine length (PSL), total lorica length including all appendages (TLL), lorica width at its widest part (LW), posterior spine angle (PSA), anterolateral dorsal spine length (ALS), anterointermediate dorsal spine length (AIS), anteromedian dorsal spine length (AMS), and lorica width beneath the anterior spines ("head width", HW)
The number of individuals measured is given between brackets next to the lake name

\begin{tabular}{lrrrrrrrrr}
\hline & LL & PSL & TLL & LW & PSA & ALS & AIS & AMS & HW \\
\hline ESU 3 & & & & & & & & & \\
Mean & 99.5 & 52.8 & 182.5 & 67.4 & 159.3 & 20.5 & 14.5 & 30.5 & 58.2 \\
Median & 100.0 & 52.6 & 182.9 & 68.2 & 159.0 & 20.8 & 14.3 & 30.0 & 58.8 \\
Min & 87.4 & 24.9 & 131.3 & 51.5 & 145.9 & 15.1 & 10.5 & 25.6 & 49.7 \\
Max & 115.0 & 90.3 & 231.5 & 77.1 & 174.2 & 24.3 & 18.2 & 36.1 & 66.8
\end{tabular}

Lakes: Caldonazzo (2), Kaltern (21), Terlago (13), Vahrn (2) ESU 4

$\begin{array}{lrrrrrrrrr}\text { Mean } & 92.8 & 0.0 & 114.8 & 63.5 & 0.0 & 14.9 & 11.9 & 22.0 & 51.8 \\ \text { Median } & 88.6 & 0.0 & 113.3 & 61.0 & 0.0 & 14.1 & 11.7 & 21.0 & 51.8 \\ \text { Min } & 82.8 & 0.0 & 106.0 & 59.4 & 0.0 & 12.3 & 11.0 & 17.0 & 49.3 \\ \text { Max } & 109.2 & 0.0 & 126.2 & 72.1 & 0.0 & 19.2 & 13.4 & 29.5 & 54.5\end{array}$

Lake: Terlago (7)

ESU 5

$\begin{array}{lrrrrrrrrr}\text { Mean } & 111.1 & 71.9 & 215.3 & 71.7 & 143.1 & 15.9 & 11.6 & 32.3 & 65.4 \\ \text { Median } & 109.9 & 75.4 & 220.3 & 75.0 & 144.0 & 16.9 & 11.4 & 32.7 & 67.8 \\ \text { Min } & 93.5 & 0.0 & 140.3 & 40.9 & 0.0 & 8.8 & 4.9 & 11.8 & 50.0 \\ \text { Max } & 129.2 & 113.1 & 266.8 & 83.2 & 165.5 & 20.9 & 16.0 & 43.5 & 75.3\end{array}$

Lakes: Glittner (43), Kaltern (1), Vahrn (1)

ESU 6

$\begin{array}{lrrrrrrrrr}\text { Mean } & 106.8 & 54.4 & 194.9 & 70.8 & 144.3 & 20.9 & 15.3 & 33.8 & 62.5 \\ \text { Median } & 108.7 & 57.4 & 199.3 & 72.3 & 155.1 & 20.7 & 15.2 & 33.8 & 63.2 \\ \text { Min } & 88.2 & 0.0 & 116.2 & 52.0 & 0.0 & 15.1 & 9.0 & 24.9 & 54.5 \\ \text { Max } & 125.7 & 81.0 & 229.7 & 77.9 & 168.3 & 26.6 & 19.5 & 41.4 & 68.4\end{array}$

Lakes: Terlago (8), Tovel (30), Vahrn (4) ESU 7

$\begin{array}{lllllllll}84.9 & 35.4 & 151.9 & 50.0 & 161.6 & 18.4 & 14.6 & 31.6 & 48.9\end{array}$

Lake: Caldonazzo (1)

ESU 8

$\begin{array}{llllllllll}\text { Mean } & 81.4 & 25.9 & 135.6 & 50.8 & 165.8 & 16.8 & 12.5 & 28.2 & 51.0 \\ \text { Median } & 83.6 & 26.0 & 138.0 & 51.7 & 166.1 & 16.9 & 12.9 & 28.0 & 51.9 \\ \text { Min } & 74.3 & 24.0 & 125.6 & 45.7 & 163.7 & 15.2 & 11.3 & 25.4 & 46.1 \\ \text { Max } & 87.1 & 28.8 & 145.3 & 52.7 & 167.2 & 18.0 & 13.1 & 31.6 & 53.4\end{array}$

Lake: Vahrn (5)
No correlation was found between phylogenetic and morphological diversity (Mantel $r=0.07$; $P=0.41)$.

\section{Discussion}

Our study indicated that eight putative ESUs of $K$. cochlearis occurred in lakes of the Trentino-South Tyrol region. This diversity may be responsible for the apparent tolerance of $K$. cochlearis to varying environmental conditions. The putative ESUs of $K$. cochlearis had an average uncorrected genetic distance in COI between 12 and 30\%, which is higher than the $3 \%$ threshold commonly used to separate species for most animals (Hebert et al., 2003; Tang et al., 2012). The general good agreement of the various methods that we used to infer putative ESUs corroborated our results. We did not consider the splitting of GMYC ESUs 3 and 6 by PTP-BA because it was not supported by the branching pattern of the tree and the other methods of species delimitation.

The wide morphological variability in $K$. cochlearis that led to the description of morphotypes 


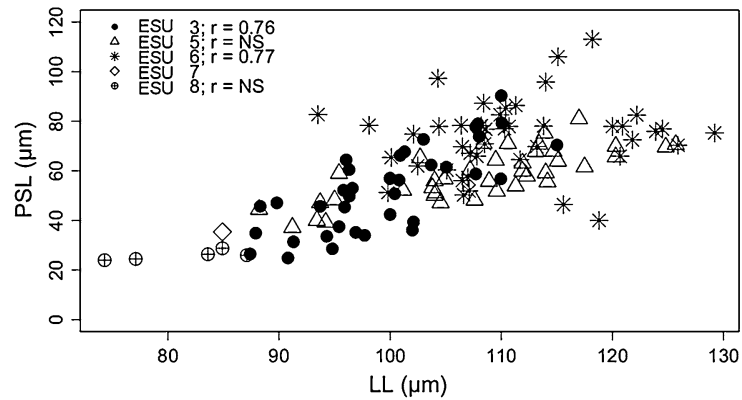

Fig. 4 Relation between posterior spine length (PSL) and lorica length (LL) for different GMYC ESUs. Numbers on axis represent length in $\mu \mathrm{m}$. Values of significantly important $(P<0.05)$ correlation coefficients are reported next to ESUs symbols

Table 5 Morphological parameters showing statistical significant differences in ANOVA between different GMYC ESUs (only significant comparisons are shown), lorica length (excluding anterior and posterior spines, LL), posterior spine length (PSL), and posterior spine angle (PSA), degrees of freedom (df), 138 specimens were measured, but ESU 7 was excluded from analyses because only specimen was measured, for ANOVA on PSL, specimens without spine were excluded (7 of ESU 4 and 3 of ESU 6), in mixed modelling of ANOVA for PSL and LL, measurements from the same lakes were modelled as correlated and in mixed modelling of ANOVA for PSA, residuals were allowed to have a different spread per lake

\begin{tabular}{llrr}
\hline Comparison & df & $t$-ratio & \multicolumn{1}{c}{$P$} \\
\hline PSA & & & \\
ESUs 3-5 & 118 & 6.23 & $<0.001$ \\
ESUs 3-8 & 118 & -2.70 & 0.038 \\
ESUs 5-6 & 118 & -4.72 & $<0.001$ \\
ESUs 5-8 & 118 & -7.01 & $<0.001$ \\
ESUs 6-8 & 118 & -4.29 & $<0.001$ \\
PSL & & & \\
ESUs 3-5 & 121 & -4.38 & $<0.001$ \\
ESUs 3-8 & 121 & 2.98 & 0.028 \\
ESUs 5-6 & 121 & 3.23 & 0.013 \\
ESUs 5-8 & 121 & 5.53 & $<0.001$ \\
ESUs 6-8 & 121 & 3.64 & 0.004 \\
LL & & & \\
ESUs 3-8 & 132 & 3.14 & 0.017 \\
ESUs 4-5 & 132 & -2.90 & 0.035 \\
ESUs 5-8 & 132 & 4.20 & $<0.001$ \\
ESUs 6-8 & 132 & 3.47 & 0.006 \\
\hline
\end{tabular}

by Lauterborn (1900) has been investigated by many researchers who tried to understand factors influencing morphology such as temperature (Green, 2005),

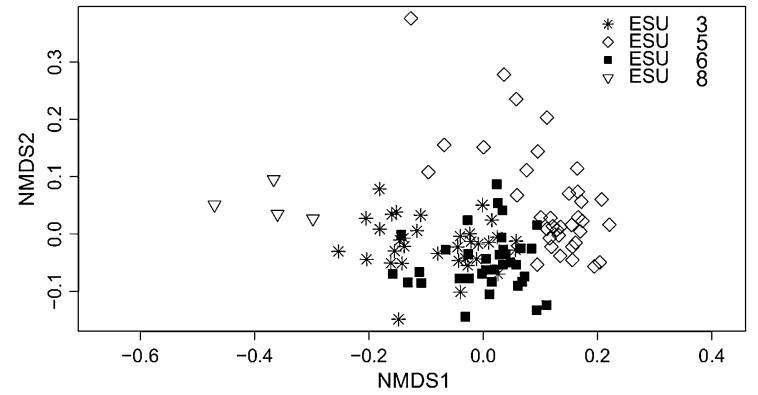

Fig. 5 Non-metric multidimensional scaling (NMDS) plot of all morphological variables. GMYC ESUs 1, 2, and 7 are excluded due to absence of morphometric data. GMYC ESU 4 and spineless specimens of ESU 6 are excluded due to lack of the posterior spine

predation (Conde-Porcuna et al., 1993), maternal effect (Stemberger \& Gilbert, 1984), or presence of distinct species (Ahlstrom, 1943; Eloranta, 1982). Our study indicated that neglecting presence of ESUs of $K$. cochlearis might have led to biased conclusions on their morphological variability and global distribution. For example, the correlation between LL and PSL is not always positive as stated by Green (2005) but seems to differ between ESUs showing no correlation or varying positive correlation. Furthermore, Green (2005) underlined that specimens with a LL of around $80 \mu \mathrm{m}$ show a wide variability in PSL. We observed an overlap of specimens of different ESUs in the range of 80-90 $\mu \mathrm{m}$. Thus, neglecting ESUs of $K$. cochlearis may lead to underestimating their phenotypic diversity.

An important characteristic for the delimitation of $K$. cochlearis morphotypes is the presence and length of the posterior spine. Our study indicated that spined and unspined (=tecta) specimens occurred in the same and different ESUs (i.e. ESUs 3 and 6, respectively). Hofmann (1983) and Green $(2005,2007)$ noted that tecta specimens could not be explained by allometric growth because specimens with spines were smaller than those without spines. Green (2005) presented three hypotheses of the origin of spineless $K$. cochlearis: 1, true tecta (appearing only in colder periods of the year as the "end" of the posterior spine reduction); 2, aspina (truly spineless, absent in the winter, LL longer than in spined form); 3, ecaudata (the same dorsal structure, occurring in summer, LL longer than in spined form). Coherent with Green's (2005) hypothesis 1 of true tecta, our study indicated based on ESU 6 that spineless forms have the same and 

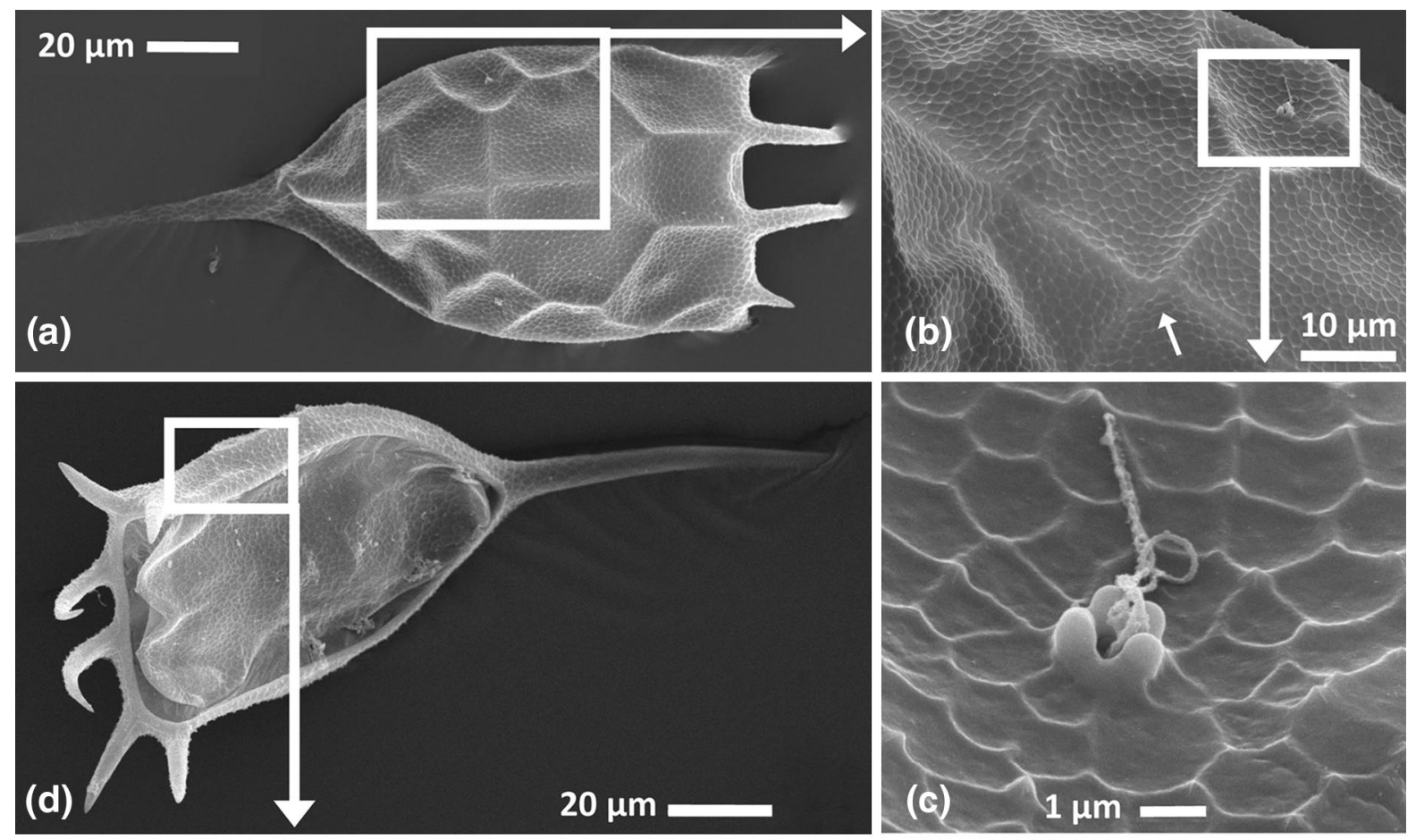

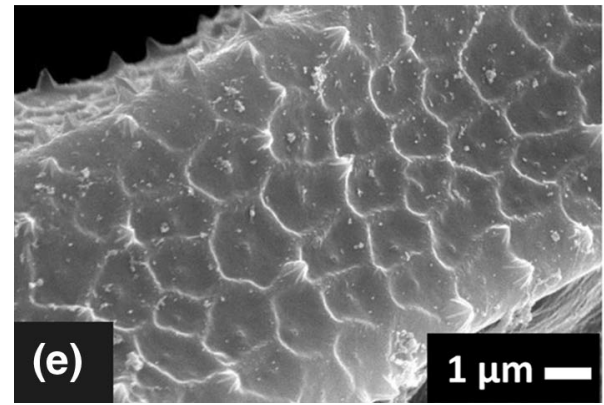

Fig. 6 SEM pictures of $K$. cochlearis, a dorsal view, b detail of bended ridge (indicated by arrow), lateral antenna, c detail of lateral antenna, $\mathbf{d}$ ventral view, and e detail of spinelets on the

smaller LL than specimens from the same ESU across different habitats. Coherent with Green's (2005) hypotheses 2 and 3, spineless specimens of ESU 4 were smaller and larger than spined morphotypes across habitats and those from the same lake. Thus, neglecting the co-occurrence of different ESUs in $K$. cochlearis leads to the odd situation that spineless specimens seem larger than spined ones. We suggest that tecta morphotypes can actually have at least two possible origins (Green's hypotheses 1 and 2/3) but delimiting true tecta from spineless aspina or ecaudata based on morphology seems quite tricky. We, furthermore, hypothesise that detailed SEM pictures of lorica facets might reveal features (such as the $X$ - intersection of the areolation and of bumps in the middle of areolation, GMYC ESU 5: (a-c), and GMYC ESU 8: (d, e)

facet or carinal facets described by Lauterborn, 1900) helpful for delimiting putative ESUs.

Spinelets and the bended ridge are other morphological features that are used in morphotype delimitation (Lauterborn, 1900) but the usefulness of spinelets was already questioned by Hofmann (1980). According to Lauterborn (1900) spinelets are characteristic for the hispida and irregularis series. However, specimens from GMYC ESUs 3 and 6 did and did not have spinelets. According to Hofmann (1980), the size of spinelets increases from spring to summer and are almost invisible during winter. In fact in our samples, specimens with spinelets occurred during summer and spring (only one was collected 
Table 6 Observed combinations of morphological characteristics present in individuals of the respective GMYC ESUs

\begin{tabular}{lllll}
\hline & Bended ridge & Spinelets & Posterior spine & Additional facets \\
\hline ESU 3 & Yes & No & Yes & No \\
ESU 3 & Yes & Yes & Yes & No \\
ESU 3 & No & No & Yes & No \\
ESU 4 & Yes & Nv & No & Yes \\
ESU 5 & Yes* & No** & Yes & No \\
ESU 6 & Yes & Yes & No & Yes \\
ESU 6 & Nv & No & Yes & No \\
\hline
\end{tabular}

Different lines were used if more than one combination was observed in a given ESU

$n v$ Not visible

* Shown in Fig. 6b, ** shown in Fig. 6e

from Lake Terlago during November), but we cannot exclude that we missed the presence of spinelets in some specimens as they were very difficult to observe. However, it seems that spinelets are only appearing (and changing in length) in some ESUs because no spinelets were ever observed in ESU 5 regardless of sampling time. Thus, we suggest that the presence of spinelets is no valid criterion for delimitating morphotypes or putative ESUs. Ahlstrom (1943) and Eloranta (1982) already pointed out that the presence of spinelets shows high variability in most $K$. cochlearis species, and here we corroborated their statement with genetic data. More detailed SEM pictures of various putative ESUs taken from different seasons are, in any case, needed in order to investigate the temporal appearance of spinelets. According to the bended ridge, specimens of ESUs 4 and 5 always showed it while it was present or absent in specimens of ESU 3. We conclude that the bended ridge is also not a valid character to delimitate ESUs. In addition to spinelets and the bended ridge, we observed small humps in the middle of the areolation section. To the best of our knowledge, we do not know about any reference to these structures. We refrain from hypothesising on their function, and if they grow, they seem to be an overlooked feature of lorica morphology. Furthermore, we provided detailed SEM images on the lateral antenna that was previously only shown by Garza-Mouriño et al. (2005, their plate 1c).

Taking into account all information on lorica morphology, different ESUs showed different morphological variabilities. Both univariate and multivariate analyses indicated that ESUs 3 and 6 were not unambiguously distinguishable based on lorica measurements showing a wide phenotypic plasticity. Contrarily, ESU 8 could be distinguished from ESU 5 based on morphology based on single measurements and NMDS. In LDA, only specimens of ESU 5 were correctly assigned in most cases, while specimens of ESU 8 did not perform that well. Specimens of ESU 8 were smaller with respect to measured characters than specimens of ESU 5. Therefore, it is possible to delimit only some putative ESUs having a more restricted phenotypic plasticity with respect to other ESUs based on detailed lorica measurements. We suggest that an analysis of specimens sampled separately during cold and warm seasons in specific water layers could provide insights into the effect of water temperature on spine development of ESUs that we may have missed by our sampling strategy.

In many of our study lakes, different ESUs of $K$. cochlearis co-occurred. Generally, it is assumed that species with similar morphology and close phylogenetic relationship might have similar niches (e.g. Wiens \& Graham, 2005; Wiens et al., 2010) and this would lead to competitive exclusion (Violle et al., 2011; Gabaldón et al., 2013). Cryptic species are not only morphologically similar but also phylogenetically closely related, and thus, the co-occurrence of cryptic species should be rarely encountered. However, cryptic species of $B$. plicatilis occur in temporal co-existence or in overlap, and their co-existence is mediated by disturbance and food partitioning (Ciros-Pérez et al., 2001a). Not only in the genus Brachionus but also in $P$. dolichoptera (Obertegger et al., 2014) co-existence of cryptic species has been observed. We found that several morphologically similar putative ESUs of $K$. cochlearis cooccurred but, at the moment, cannot infer their niche 
partitioning because of missing information regarding their depth distribution. Furthermore, our study indicated no link between phylogenetic and morphological diversity of putative ESUs. Similarly, Gabaldón et al. (2013) found no difference between cryptic species of $B$. plicatilis for key parameters (i.e. clearance rates, starvation tolerance and predation susceptibility) related to body size. Recently, co-existence of cryptic species was linked to a negative feedback based on sex-based mechanisms that lead to stable co-existence (MonteroPau et al., 2011).

In conclusion, our study indicates that $K$. cochlearis is composed of eight putative ESUs based on mtDNA, as indicated by three different methods. The generally good agreement between these methods enhances our inference on species diversity. Several morphological characteristics such as presence/absence of the posterior spine, spinelets, and bended ridge seem to be of poor value to discriminate ESUs. However, when all lorica measurements are taken together in a multivariate statistical approach, ESU 5 could be distinguished from ESU 8. More detailed morphological research is needed for a longer period to understand the morphological variations of $K$. cochlearis ESUs.

Acknowledgments Open access funding provided by University of Innsbruck and Medical University of Innsbruck. This work was supported by FIRST PhD School Program of the Fondazione Edmund Mach (FEM). We would like to thank Danilo Tait (APPA Bozen-South Tyrol) for environmental data; Massimo Pindo, the technical staff of the Sequencing Platform (FEM-CRI), and Chiara Rossi (FEM) for help with PCR Protocols; Cristina Bruno (FEM), Vezio Cottarelli, Gabriella Gambellini, and Anna Rita Taddei (Tuscia University) for their assistance with SEM pictures. We also thank the Reviewers including Jean-François Flot and the Guest Editors of Hydrobiologia for their suggestions that improved this article.

Open Access This article is distributed under the terms of the Creative Commons Attribution 4.0 International License (http:// creativecommons.org/licenses/by/4.0/), which permits unrestricted use, distribution, and reproduction in any medium, provided you give appropriate credit to the original author(s) and the source, provide a link to the Creative Commons license, and indicate if changes were made.

\section{References}

Ahlstrom, E. H., 1943. A revision of the rotatorian genus Keratella with descriptions of three new species and five new varieties. Bulletin of the American Museum of Natural History 80: 411-457.
Arthofer, W., H. Rauch, B. Thaler-Knoflach, K. Moder, C. Muster, B. C. Schlick-Steiner \& F. M. Steiner, 2013. How diverse is Mitopus morio? Integrative taxonomy detects cryptic species in a small-scale sample of a widespread harvestman. Molecular Ecology 22: 3850-3863.

Berziņš, B. \& B. Pejler, 1989a. Rotifer occurrence in relation to temperature. Hydrobiologia 175: 223-231.

Berzinš̌, B. \& B. Pejler, 1989b. Rotifer occurrence in relation to oxygen content. Hydrobiologia 175: 223-231.

Berzinšs, B. \& B. Pejler, 1989c. Rotifer occurrence and trophic degree. Hydrobiologia 182: 171-180.

Bielanska-Grajner, I., 1995. Influence of temperature on morphological variation in populations of Keratella cochlearis (Gosse) in Rybnik Reservoir. Hydrobiologia 313: 139-146.

Blanco-Bercial, L., A. Cornils \& N. Copley, 2014. DNA barcoding of marine copepods: assessment of analytical approaches to species identification. PLoS Currents Tree of Life 6: 1-40.

Ciros-Pérez, J., M. Carmona \& M. Serra, 2001a. Resource competition between sympatric sibling rotifer species. Limnology and Oceanography 46: 1511-1523.

Ciros-Pérez, J., A. Gómez \& M. Serra, 2001b. On the taxonomy of three sympatric sibling species of the Brachionus plicatilis (Rotifera) complex from Spain, with the description of B. ibericus n. sp. Journal of Plankton Research 23: 1311-1328.

Conde-Porcuna, J. M., R. Morales-Baquero \& L. Cruz-Pizarro, 1993. Effectiveness of the caudal spine as a defense mechanism in Keratella cochlearis. Hydrobiologia 255/256: 283-287.

Dellicour, S. \& J.-F. Flot, 2015. Delimiting species-poor data sets using single molecular markers: a study of barcode gaps, haplowebs and GMYC. Systematic Biology 64: 900-908.

Derry, A. M., P. D. N. Hebert \& E. E. Prepas, 2003. Evolution of rotifers in saline and subsaline lakes: a molecular phylogenetic approach. Limnology and Oceanography 48: 675-685.

Drummond, A. J., M. A. Suchard \& D. Xie, 2012. Bayesian phylogenetics with BEAUti and the BEAST 1.7. Molecular Biology and Evolution 29: 1969-1973.

Eloranta, P., 1982. Notes on the morphological variation of the rotifer species Keratella cochlearis (Gosse) S.L. in one eutrophic pond. Journal of Plankton Research 4: 299-312.

Ezard, T., T. Fujisawa \& T. Barraclough, 2009. Splits: species' limits by threshold statistics. R Package Version 1.0-14/r31 [available on internet at http://R-Forge.R-project.org/ projects/splits/].

Foissner, W., 2006. Biogeography and dispersal of microorganisms: a review emphasizing protists. Acta Protozoologica 45: 111-136.

Folmer, O., M. Black, W. Hoeh, R. Lutz \& R. Vrijenhoek, 1994. DNA primers for amplification of mitochondrial cytochrome $c$ oxidase subunit I from diverse metazoan invertebrates. Molecular Marine Biology and Biotechnology 3: 294-299.

Fontaneto, D., 2014. Molecular phylogenies as a tool to understand diversity in rotifers. International Review of Hydrobiology 99: 178-187.

Fontaneto, D., J.-F. Flot \& C. Q. Tang, 2015. Guidelines for DNA taxonomy, with a focus on the meiofauna. Marine Biodiversity 45: 433-451. 
Fournier, D., M. Tindo, M. Kenne, P. S. Mbenoun Masse, V. Van Bossche, E. De Coninck \& S. Aron, 2012. Genetic structure, nestmate recognition and behaviour of two cryptic species of the invasive big-headed ant Pheidole megacephala. PLoS One 7: 2.

Fujisawa, T. \& T. G. Barraclough, 2013. Delimiting species using single-locus data and the generalized mixed yule coalescent approach: a revised method and evaluation on simulated data sets. Systematic Biology 62: 707-724.

Funk, D. J. \& K. E. Omland, 2003. Frequency, causes, and consequences, with insights from animal mitochondrial DNA. Annual Review of Ecology, Evolution, and Systematics 34: 397-423.

Gabaldón, C., J. Montero-Pau, M. Serra \& M. J. Carmona, 2013. Morphological similarity and ecological overlap in two rotifer species. PLoS One 8: 23-25.

García-Morales, E. \& M. Elías-Gutiérrez, 2013. DNA barcoding of freshwater Rotifera in Mexico: evidence of cryptic speciation in common rotifers. Molecular Ecology Resources 13: 1097-1107.

Garza-Mouriño, G., M. Silva-Briano, S. Nandini, S. S. S. Sarma \& M. E. Castellanos-Páez, 2005. Morphological and morphometrical variations of selected rotifer species in response to predation: a seasonal study of selected brachionid species from Lake Xochimilco (Mexico). Hydrobiologia 546: 169-179.

Gaston, K., 2000. Global patterns in biodiversity. Nature 405: 220-227.

Gilbert, J. \& E. Walsh, 2005. Brachionus calyciflorus is a species complex: mating behavior and genetic differentiation among four geographically isolated strains. Hydrobiologia 546: 257-265.

Gómez, Á. \& M. Serra, 1995. Behavioral reproductive isolation among sympatric strains of Brachionus plicatilis Müller 1786: insights into the status of this taxonomic species. Hydrobiologia 313-314: 111-119.

Gómez, A., M. Serra, G. R. Carvalho \& D. H. Lunt, 2002. Speciation in ancient cryptic species complexes: evidence from the molecular phylogeny of Brachionus plicatilis (Rotifera). Journal of Evolutionary Biology 56: 1431-1444.

Gómez, A. \& T. W. Snell, 1996. Sibling species and cryptic speciation in the Brachionus plicatilis species complex (Rotifera). Journal of Evolutionary Biology 9: 953-964.

Green, J., 1981. Altitude and seasonal polymorphism of Keratella cochlearis (Rotifera) in lakes of the Auvergne, Central France. Biological Journal of the Linnean Society 16: $55-61$.

Green, J., 1987. Keratella cochlearis (Gosse) in Africa. Hydrobiologia 147: 3-8.

Green, J., 2005. Morphological variation of Keratella cochlearis (Gosse) in a backwater of the River Thames. Hydrobiologia 546: 189-196.

Green, J., 2007. Morphological variation of Keratella cochlearis (Gosse) in Myanmar (Burma) in relation to zooplankton community structure. Hydrobiologia 593: 5-12.

Guindon, S. \& O. Gascuel, 2003. A simple, fast, and accurate algorithm to estimate large phylogenies by maximum likelihood. Systematic Biology 52: 696-704.

Hebert, P., J. Witt \& S. Adamowicz, 2003. Phylogeographical patterning in Daphnia ambigua: regional divergence and intercontinental cohesion. Limnology and Oceanography 48: 261-268.

Hofmann, W., 1980. On morphological variation in Keratella cochlearis populations from Holstein Lakes. Hydrobiologia 73: 255-258.

Hofmann, W., 1983. On temporal variation in the Keratella cochlearis the question of Lauterborn cycles. Hydrobiologia 101: 247-254.

Hothorn, T., F. Bretz \& P. Westfall, 2008. Simultaneous inference in general parametric models. Biometrical Journal 50: 346-363.

Keane, T., C. Creevey \& M. Pentony, 2006. Assessment of methods for amino acid matrix selection and their use on empirical data shows that ad hoc assumptions for choice of matrix are not justified. BMC Evolutionary Biology 6: 29.

Koste, W., 1978. Rotatoria. Die Radertiere Mitteleuropas, 2nd ed. Gebrüder Borntraeger, Berlin, V. 1, text, 673 p; V. 2, plates, $476 \mathrm{p}$.

Lauterborn, R., 1900. Der Formenkreis von Anuraea cochlearis. Ein Beitrag zur Kenntnis der Variabilität bei Rotatorien. I. Teil: Morphologische Gliederung des Formenkreises. In Verhandlungen des Naturhistorischmedizinischen Vereins zu Heidelberg, Vol. 6. 412-448.

Leasi, F., C. Q. Tang, W. H. De Smet \& D. Fontaneto, 2013. Cryptic diversity with wide salinity tolerance in the putative euryhaline Testudinella clypeata (Rotifera, Monogononta). Zoological Journal of the Linnean Society 168: 17-28.

Malekzadeh-Viayeh, R., R. Pak-Tarmani, N. Rostamkhani \& D. Fontaneto, 2014. Diversity of the rotifer Brachionus plicatilis species complex (Rotifera: Monogononta) in Iran through integrative taxonomy. Zoological Journal of the Linnean Society 170: 233-244.

Mills, S., J. A. Alcántara-Rodríguez, J. Ciros-Pérez, A. Gómez, A. Hagiwara, K. Hinson Galindo, C. D. Jersabek, R. Malekzadeh-Viayeh, F. Leasi, J.-S. Lee, D. B. M. Welch, S. Papakostas, S. Riss, H. Segers, M. Serra, R. Shiel, R. Smolak, T. W. Snell, C.-P. Stelzer, C. Q. Tang, R. L. Wallace, D. Fontaneto \& E. J. Walsh, 2016. Fifteen species in one: deciphering the Brachionus plicatilis species complex (Rotifera, Monogononta) through DNA taxonomy. Hydrobiologia. doi:10.1007/s10750-016-2725-7.

Montero-Pau, J., E. Ramos-Rodriguez, M. Serra \& A. Gómez, 2011. Long-term coexistence of rotifer cryptic species. PLoS One 6: 6.

Obertegger, U., D. Fontaneto \& G. Flaim, 2012. Using DNA taxonomy to investigate the ecological determinants of plankton diversity: explaining the occurrence of Synchaeta spp. (Rotifera, Monogononta) in mountain lakes. Freshwater Biology 57: 1545-1553.

Obertegger, U., G. Flaim \& D. Fontaneto, 2014. Cryptic diversity within the rotifer Polyarthra dolichoptera along an altitudinal gradient. Freshwater Biology 59: 2413-2427.

Oksanen, J., F. G. Blanchet, R. Kindt, P. Legendre, P. R. Minchin, R. B. O'Hara, G. L. Simpson, P. Solymos, M. H. H. Stevens \& H. Wagner, 2015. Vegan: Community Ecology Package. R Package Version 2.3-0 [available on internet at http://CRAN.R-project.org/package=vegan].

Ortells, R., A. Gomez \& M. Serra, 2003. Coexistence of cryptic rotifer species: ecological and genetic characteristics of Brachionus plicatilis. Freshwater Biology 48: 2194-2202. 
Papakostas, S., E. Michaloudi, K. Proios, M. Brehm, L. Verhage, J. Rota, C. Peña, G. Stamou, V. L. Pritchard, D. Fontaneto \& S. A. J. Declerck, 2016. Integrative taxonomy recognizes evolutionary units despite widespread mitonuclear discordance: evidence from a rotifer cryptic species complex. Systematic Biology 65: 508-524.

Papakostas, S., E. Michaloudi, A. Triantafyllidis, I. Kappas \& T. J. Abatzopoulos, 2012. Allochronic divergence and clonal succession: two microevolutionary processes sculpturing population structure of Brachionus rotifers. Hydrobiologia 700: 33-45.

Pinheiro, J., D. Bates, S. DebRoy \& D. Sarkar. 2012. Linear and nonlinear mixed effects models CRAN-package nlme [available on internet at http://cran.r-project.org/web/ packages/nlme/index.html].

Puillandre, N., A. Lambert, S. Brouillet \& G. Achaz, 2012. ABGD, Automatic Barcode Gap Discovery for primary species delimitation. Molecular Ecology 21: 1864-1877.

Quinn, G. P. \& M. J. Keuogh, 2002. Experimental Design and Data Analysis for Biologists. Cambridge University Press, Cambridge: 1-537.

R Core Team, 2012. R: a language and environment for statistical computing. R Foundation for Statistical Computing, Vienna [available on internet at http://www.Rproject.org/].

Rambaut, A., M. A. Suchard, D. Xie \& A. J. Drummond, 2014. Tracer v1.6 [available on internet at http://beast.bio.ed.ac. uk/Tracer].

Ruttner-Kolisko, A., 1974. Plankton rotifers: biology and taxonomy. Binnengewässer 26(1), 146 pp.

Schlick-Steiner, B. C., F. M. Steiner, K. Moder, B. Seifert, M. Sanetra, E. Dyreson, C. Stauffer \& E. Christian, 2006. A multidisciplinary approach reveals cryptic diversity in Western Palearctic Tetramorium ants (Hymenoptera: Formicidae). Molecular Phylogenetics and Evolution 40: 259-273.

Schröder, T. \& E. J. Walsh, 2007. Cryptic speciation in the cosmopolitan Epiphanes senta complex (Monogononta, Rotifera) with the description of new species. Hydrobiologia 593: 129-140.

Schröder, T. \& E. J. Walsh, 2010. Genetic differentiation, behavioural reproductive isolation and mixis cues in three sibling species of Monogonont rotifers. Freshwater Biology 55: 2570-2584.
Segers, H. \& W. H. De Smet, 2008. Diversity and endemism in Rotifera: a review, and Keratella Bory de St Vincent. Biodiversity and Conservation 17: 303-316.

Stemberger, R. S. \& J. J. Gilbert, 1984. Spine development in the rotifer Keratella cochlearis: induction by cyclopoid copepods and Asplanchna. Freshwater Biology 14: 639-647.

Suatoni, E., S. Vicario, S. Rice, T. Snell \& A. Caccone, 2006. An analysis of species boundaries and biogeographic patterns in a cryptic species complex: the rotifer-Brachionus plicatilis. Molecular Phylogenetics and Evolution 41: 86-98.

Tang, C. Q., F. Leasi, U. Obertegger, A. Kieneke, T. G. Barraclough \& D. Fontaneto, 2012. The widely used small subunit $18 \mathrm{~S}$ rDNA molecule greatly underestimates true diversity in biodiversity surveys of the meiofauna. Proceedings of the National Academy of Sciences of USA 109: 16208-16212.

Tang, C. Q., A. M. Humphreys, D. Fontaneto \& T. G. Barraclough, 2014. Effects of phylogenetic reconstruction method on the robustness of species delimitation using single-locus data. Methods in Ecology and Evolution 5: 1086-1094.

Venables, W. N. \& B. D. Ripley, 2002. Modern Applied Statistics with S, 4th ed. Springer, New York.

Violle, C., D. R. Nemergut, Z. Pu \& L. Jiang, 2011. Phylogenetic limiting similarity and competitive exclusion. Ecology Letters 14: 782-787.

Wiens, J. J. \& C. H. Graham, 2005. Niche conservatism: integrating evolution, ecology, and conservation biology. Annual Review of Ecology, Evolution and Systematics 36: 519-539.

Wiens, J. J., D. D. Ackerly, A. P. Allen, B. L. Anacker, L. B. Buckley, H. V. Cornell, E. I. Damschen, T. Jonathan Davies, J. A. Grytnes, S. P. Harrison, B. a. Hawkins, R. D. Holt, C. M. McCain \& P. R. Stephens, 2010. Niche conservatism as an emerging principle in ecology and conservation biology. Ecology Letters 13: 1310-1324.

Xi, Y., H. Jin, P. Xie \& X. Huang, 2011. Morphological variation of Keratella cochlearis (Rotatoria) in a shallow, eutrophic subtropic Chinese lake. Journal of Freshwater Ecology 17: 37-41.

Zhang, J., P. Kapli \& P. Pavlidis, 2013. A general species delimitation method with applications to phylogenetic placements. Bioinformatics 29: 2869-2876. 